\title{
INFLUENZA VACCINATION IN AUSTRIA: PERSISTENT RESISTANCE AND IGNORANCE TO INFLUENZA PREVENTION AND CONTROL
}

\author{
Ursula Kunze', Gabriela Böhm¹, Bernhard Prager², Ernest Groman ${ }^{1}$ \\ ${ }^{1}$ Centre for Public Health, Institute of Social Medicine, Medical University of Vienna, Vienna, Austria \\ ${ }^{2}$ Austrian Association of Vaccine Manufacturers, Vienna, Austria
}

\begin{abstract}
SUMMARY
Objective: In the Austrian population approximately 350,000-400,000 cases and 1,000-1,200 deaths are observed during an average epidemic, which puts influenza-related deaths on top of the list of vaccine-preventable cases of death. In face of extensive vaccination recommendations, the current vaccination rate of the general population of about $6 \%$ is one of the lowest worldwide. The objective of this study was to provide an update regarding the use of influenza vaccination in Austria over the period 1982-2015.

Methods: This paper presents data on influenza vaccine use in Austria displayed by the number of distributed doses per 1,000 population over a period of 33 years. Further data was collected from representative population-based telephone surveys.

Results: Austria has always been among the countries with a low number of distributed doses of influenza vaccine. The highest number ever was reached in 2006 with 142 doses/1,000. From 2007 onwards, a steady decrease happened to 62 doses/1,000 in the 2015/16 season, which corresponds to the level of the mid-nineties.

Conclusion: Despite the fact that Austria is a country with comprehensive recommendations for influenza vaccination, this vaccination continues to be misjudged by the Austrian population and many areas of the medical system. From a public health point of view, this situation is not acceptable. Efforts must be increased to attain a much higher vaccination rate, e.g. the importance of the healthcare workers' influence must be recognized, the options of social marketing have to be utilized and studies on the main barriers in Austria are urgently needed.
\end{abstract}

Key words: influenza, vaccination, vaccine use, dose distribution, Austria

Address for correspondence: U. Kunze, Institute of Social Medicine, Centre for Public Health Medical University of Vienna, Kinderspitalgasse 15, A-1090 Vienna, Austria. E-mail: ursula.kunze@meduniwien.ac.at

https://doi.org/10.21101/cejph.a5010

\section{INTRODUCTION}

Worldwide, between 5 to $10 \%$ of adults and 20 to $30 \%$ of children are attacked by influenza annually resulting in about $3-5$ million severe cases and 250,000-500,000 deaths (1). Important risk groups for severe disease are the elderly (particularly those over the age of 65), people of any age with underlying chronic diseases, children under the age of 5 and pregnant women. Beside serious clinical cases and deaths, the large numbers of mild to moderate cases are also of substantial economic impact. Time off work, losses to production, pressure and costs on the health and social care services are the main factors (1-3). However, about 40,000 influenza deaths occur annually during an average epidemic in the European Union (EU) population (4), whereas in the Austrian population approximately $350,000-400,000$ cases and 1,000-1,200 deaths are observed (5). This puts influenzarelated deaths on top of the list of vaccine-preventable cases of death in Austria.

Data on influenza vaccination rates is scarce, worldwide, and in Europe, data is available only for some countries provided by the Vaccine European New Integrated Collaboration Effort (VENICE) (6). Because Austria is unable to provide any group- or age-specific coverage data, it is missing in the ECDC statistics and Eurosurveillance reports. In face of extensive vaccination recommendations, the current vaccination rate of the general population in Austria of about 6\% (2015/16) is one of the lowest in the world.

The World Health Organization (WHO) and the European Commission have set a target of $75 \%$ of people aged over 65 years receiving vaccination against influenza by the $2014 / 15$ season (7, 8). A recent Austrian study revealed a vaccination coverage rate in patients $>65$ years in primary care of $31 \%$ (2010/11 season) (9). Hence, Austria has by far failed the aim of $75 \%$ coverage in this age group, together with several other countries such as Romania (7\%), Slovenia (11\%), Poland (13\%), Croatia (21\%), or Lithuania (22\%) (all 2014/15 data) (10). These numbers are among the lowest in the highly affected age group of $>65$ years in Europe. Countries close to the target of $75 \%$ in the $2014 / 15$ season were the UK (73\%) and the Netherlands $(67 \%)$, and countries with comparable high rates enclose Ireland (60\%), Spain (56\%), Italy (49\%), and France (48\%) (10).

With respect to little data on influenza vaccination rates, an alternative to estimate vaccination coverage is recording of dose distribution, which has been done by different research groups since the early 1990s. To date, data on seasonal influenza vaccine 
dose distribution in 195 countries (including Austria) has been cumulated (11).

Two earlier publications have reported Austria's influenza vaccine use from 1982 to 2003 and from 1982-2011 $(12,13)$. The present study provides an update including data from four additional influenza seasons, from 2012/13 to 2015/16.

\section{Extensive Influenza Vaccination Recommendations in Austria}

National recommendations to vaccinate the elderly (over the age of 60 or 65) and those with underlying high-risk conditions are implemented in the most developed and rapidly developing countries. Austria is still among the countries with the most extensive influenza vaccination recommendations worldwide (10, 14). The general recommendation for everyone was established in 2002 (in the US not until 2010). Austria, Belgium and Ireland are the only countries in Europe with national recommendations for all people over the age of 50 and only Austria, Estonia, Poland, and Slovakia recommend vaccination for all children over the age of 6 months (10).

Significant recent supplements to the national influenza vaccination recommendations were the specific recommendations for obese people in 2011 and for all children > 6 months in 2014 (14). There is still no comprehensive reimbursement for the vaccination costs implemented (only some regional activities).

\section{MATERIALS AND METHODS}

Four publications by independent investigators and the European Scientific Working Group on Influenza (ESWI), covering the three study periods 1980 to 1992,1993 to 1995 and 1996 to 2003 , have provided a foundation for understanding the macroepidemiology of influenza vaccination throughout the world (15-18). Subsequently, the International Federation of Pharmaceutical Manufacturers and Associations (IFPMA) Influenza Vaccine Supply (IVS) Task Force developed a survey methodology to supply continuous information on a regional or worldwide basis $(19,20)$. In 2010, the IFPMA IVS updated and extended this database, which then offered a unique resource for information about the seasonal influenza vaccine distribution in 157 countries for the 6-year study period from 2004 to 2009 (19). A recent continuing publication discloses little progress in the estimated global vaccination coverage in 195 countries over the period from 2004 to 2013 (11). Vaccine use data within all these studies have been represented as dose distribution per 1,000 population $(n / 1,000)$.

Additional new data included in this update study covers the years 2012 to 2015 and was obtained by calculating the number of actually distributed doses of influenza vaccine in the Austrian market only. The Austrian Association of Vaccine Manufacturers provided the numbers. Data of the earlier years (2005 to 2011) was already presented in the previous study (13).

Further data presented was collected from representative population-based computer-assisted telephone surveys (CATI), initiated by the Austrian Association of Vaccine Manufacturers. Those surveys were performed annually at the end of the seasons $2012 / 13$ to $2015 / 16$. The interviews were performed with 1,000 respondents over 14 years of age. The respondents were selected at random from telephone books. Within these surveys, among others, the question "Have you been vaccinated against influenza in the past 6 months?" was sampled in the general population and the age groups $>60$ and $>70$ years.

\section{RESULTS}

The Austrian results of the first three study periods (1980 to 1992, 1993 to 1995 , and 1996 to 2003), and the fourth study period covering the years 2004 to 2011 have been described extensively in two earlier papers $(12,13)$. In a nutshell, there was a clear increase of influenza vaccination use in Austria between 1982 and 2003 from a very low level of 20 doses up to 127 doses/1,000 (Table 1). The highest number of distributed doses ever was reached in 2006 with 142 doses/1,000. However, the numbers for the last years show that, from 2007 onwards, a steady decrease happened to 81 doses in 2011 (13) and a further decrease to only 62 doses/1,000 in the 2015/16 season, which corresponds to the level of the mid-nineties $(12,15)$ (Table 1). For additional information, Table 2 illustrates the vaccination rates (\%) of the Austrian population for the seasons 2005/06 to $2015 / 16$. The highest vaccination rate was reached in $2006 / 07$ with $15 \%$. Hence, the vaccination rate of the Austrian population has been among the lowest worldwide.

Table 1. Annual number of doses of influenza vaccine distributed in Austria, $n / 1,000$ population, 1982-2015

\begin{tabular}{|c|c|c|}
\hline Study period & Year & Doses \\
\hline \multirow{2}{*}{$\begin{array}{l}\text { 1980-1992 (15) } \\
\text { 1980, } 1981 \text { no data available }\end{array}$} & 1982-1991 & $\sim 20$ \\
\hline & 1992 & 23 \\
\hline \multirow{3}{*}{ 1993-1995 (16) } & 1993 & 40 \\
\hline & 1994 & 45 \\
\hline & 1995 & 54 \\
\hline \multirow{7}{*}{$\begin{array}{l}1997-2003(17,18) \\
1996 \text { no data available }\end{array}$} & 1997 & 77 \\
\hline & 1998 & 85 \\
\hline & 1999 & 107 \\
\hline & 2000 & 118 \\
\hline & 2001 & 121 \\
\hline & 2002 & 106 \\
\hline & 2003 & 127 \\
\hline \multirow{11}{*}{$\begin{array}{l}2005-2015(\#, 11,13) \\
2004 \text { no data available }\end{array}$} & 2005 & 138 \\
\hline & 2006 & 142 \\
\hline & 2007 & 129 \\
\hline & 2008 & 113 \\
\hline & 2009 & 117 \\
\hline & 2010 & 87 \\
\hline & 2011 & 81 \\
\hline & 2012 & 74 \\
\hline & 2013 & 52 \\
\hline & 2014 & 65 \\
\hline & 2015 & 62 \\
\hline
\end{tabular}

\# Austrian Association of Vaccine Manufacturers 
Table 2. Estimated vaccination rate of the Austrian population in \%, seasons 2005/06-2015/16

\begin{tabular}{|l|c|c|c|c|c|c|c|c|c|c|c|}
\hline Season & $\mathbf{2 0 0 5 / 0 6}$ & $\mathbf{2 0 0 6 / 0 7}$ & $\mathbf{2 0 0 7 / 0 8}$ & $\mathbf{2 0 0 8 / 0 9}$ & $\mathbf{2 0 0 9 / 1 0}$ & $\mathbf{2 0 1 0 / 1 1}$ & $\mathbf{2 0 1 1 / 1 2}$ & $\mathbf{2 0 1 2 / 1 3}$ & $\mathbf{2 0 1 3 / 1 4}$ & $\mathbf{2 0 1 4 / 1 5}$ & $\mathbf{2 0 1 5 / 1 6}$ \\
\hline Population $^{1}$ & $8,225.278$ & $8,267.948$ & $8,295.189$ & $8,321.541$ & $8,341.483$ & $8,361.069$ & $8,388.534$ & $8,426.311$ & $8,477.230$ & $8,543.932$ & $8,629.519$ \\
\hline $\begin{array}{l}\text { Vaccination } \\
\text { rate }\end{array}$ & $13.2 \%$ & $15.4 \%$ & $12.9 \%$ & $11.3 \%$ & $11.7 \%$ & $7.9 \%$ & $8.3 \%$ & $7.4 \%$ & $5.2 \%$ & $6.5 \%$ & $6.1 \%$ \\
\hline
\end{tabular}

${ }^{1}$ Statistics Austria, annual average population (25)

Table 3. Influenza vaccination rate in \% from telephone survey data over the seasons 2012/13-2015/16 in Austria

\begin{tabular}{|l|c|c|c|}
\hline Influenza season & $\begin{array}{c}\text { General population } \\
(\%)\end{array}$ & $\begin{array}{c}>60 \text { years } \\
(\%)\end{array}$ & $\begin{array}{c}>70 \text { years } \\
(\%)\end{array}$ \\
\hline $2012 / 13$ & 10 & 15 & 22 \\
\hline $2013 / 14$ & 9 & 13 & 23 \\
\hline $2014 / 15$ & 7 & 11 & 16 \\
\hline $2015 / 16$ & 8 & 14 & 14 \\
\hline
\end{tabular}

The telephone survey data of the self-reported vaccination rate in the general Austrian population from the seasons 2012/13 to $2015 / 16$ disclose a similar picture confirming the overall data of distributed doses (Table 3 ). The self-reported vaccination rates in the elderly are somewhat higher as in the younger age groups but still are much too low to achieve appropriate protection in these vulnerable age groups and by far failing the $75 \%$ of people $>65$ years receiving vaccination against influenza recommended by the WHO and European Commission. The decreasing trend is obvious especially in the age group $>70$ years, where the vaccination rate fell from $22 \%$ in the $2012 / 13$ season to $14 \%$ in the 2015/16 season.

\section{DISCUSSION}

Globally, there has been an $87 \%$ increase in the total number of distributed influenza doses between 2004 and 2013 from approximately 262 million to 490 million with variation by WHO regions, however, the rate of growth has dramatically slowed since 2008, with an approximate 12\% increase between 2008 and 2013 (436 to 490) (11). In the Euroregion, the increase between 2004 and 2013 was $9.6 \%$, but the number of distributed doses decreased by $31.5 \%$ between 2008 and 2013 .

Despite international consensus on the need to increase vaccination rates $(7,8,21,22)$ a continued negative trend for dose distribution in the Euroregion has been observed (11). The number of vaccine doses dropped in 38 of 53 countries $(72 \%)$ in the Euroregion and only 11 countries achieved increased rates.

In most countries the vaccination coverage for the elderly does not meet the target of $75 \%$. Moreover, for all other risk groups, (very limited) available data describe low and insufficient vaccination coverage rates in all target groups, including healthcare workers $(21,22)$. Out of about 180 million Europeans for whom influenza vaccination is recommended, only 80 million are vaccinated. To reach the $75 \%$ vaccination coverage target in the elderly, additional 57.4 million persons would need to be vaccinated. Full implementation of the $75 \%$ target in the EU-27 countries, would avert average annual influenza related events to additional
1.6 to 1.7 million cases, 23,800 to 31,400 hospitalization, 9,800 to 14,300 deaths and 767,800 physician visits and 883,800 to $1,015,100$ lost days of work yearly (23).

In Austria, after increases in the use of influenza vaccinations from 1982 to 2006 a steady decrease to the mid-nineties level (62 in 2015/16) was observed. Although also facing a considerable decreasing trend in the past few years, the majority of European countries was much more successful than Austria, the approximate figures for the UK were 280 doses, Finland 234 doses, the Netherlands 234 doses, Germany 224 doses, Malta 205 doses, Italy, Belgium and Ireland 190 doses, and Spain 170 doses (all 2013) (11).

The vaccination rate of the Austrian population further dropped from the very low level of $<10 \%$ in $2010 / 11$ (13) to about $6 \%$ in $2015 / 16$. An Austrian study showed an influenza vaccination rate of $14 \%$ among patients at GPs offices in the 2010/11 season (24).

Austria has one of the best health systems worldwide; however, its influenza vaccination rates are disastrous. The high number of available products does not automatically lead to broad use of influence vaccines despite excellent recommendations. Obviously, there is an urgent need for additional supportive initiatives from authorities to achieve acceptable vaccination coverage rates.

The Austrian population, and unfortunately many parts of the medical system, have shown distinct ignorance regarding the prevention and control of influenza in the past. Obviously, the misjudgement of this dangerous infectious disease continues. The possible reasons behind the development of this situation have been discussed in an earlier study (13) and have not changed until today: mistaking influenza for an influenza-like illness (ILI), lack of social marketing, no financial reimbursement, disunity within the health system, negative attitudes of healthcare workers, generally low vaccination rates in adults, and the lack of recommendations of a (trusted family) doctor for the vaccine. The lack of officially published vaccination coverage target rates for risk groups could be another major contributing factor.

\section{CONCLUSION}

Despite the fact that Austria is a country with comprehensive recommendations for influenza vaccination, this disease continues to be misjudged by the Austrian population and many areas of the medical system. The implementation of the recommendations still does not take place, which is reflected by a very low vaccination rate of about $6 \%$ of the general population and only of about $14 \%$ of the highly affected group of the elderly $(2015 / 16)$. This persistent status causes frustration for all those who work in the field of influenza prevention in Austria.

From a public health point of view, this situation is not acceptable. Substantial changes have to be made and efforts must 
be increased to attain a much higher vaccination rate in Austria. The importance of the healthcare workers' influence must be recognized. Austrian healthcare workers need to be better informed and must apply the findings of evidence-based medicine. This should lead to more active recommendation and prescriptions of influenza vaccination for their patients and the use of the right antiviral therapy in cases of infection (neuraminidase-blocking therapeutics). Additionally, the options of social marketing must be utilized to increase awareness in both the general population and the medical system, though legal promotion restrictions for prescription medicines limit the use of such initiatives. Effective communication by health authorities and healthcare policy is essential. Future studies about the use of the influenza vaccine and the main barriers in Austria would be necessary.

\section{Conflict of Interests}

Ursula Kunze, Gabriela Böhm, Ernest Groman: none. Bernhard Prager is an employee of Sanofi Pasteur and acts voluntarily as general secretary of the Austrian Association of Vaccine Manufactures. In this function he contributed by providing raw data for calculation of coverage data and revision of the manuscript.

\section{REFERENCES}

1. Vaccines against influenza WHO position paper - November 2012. Wkly Epidemiol Rec. 2012 Nov 23;87(47):461-76.

2. World Health Organization. Influenza. Fact sheet No 211 [Internet]. Geneva: WHO; 2003 [cited 2016 Jun 15]. Available from: http://www. who.int/mediacentre/factsheets/2003/fs211/en.

3. Seasonal human influenza and vaccination - the facts [Internet]. Solna: ECDC; 2009 [cited 2016 Sep 19]. Available from: http://www.ecdc. europa.eu/en/healthtopics/Documents/0712_seasonal_human_influenza_vaccination.pdf.

4. European Centre for Disease Prevention and Control. Fact sheet for health professionals on seasonal influenza [Internet]. Solna: ECDC [cited 2016 Jun 15]. Available from: http://ecdc.europa.eu/en/healthtopics/seasonal influenza/basic_facts/Pages/factsheet_professionals_seasonal_influenza. aspx.

5. Kou HW, Schmid D, Liu YL, Allerberger F. Influenza-related excess mortality, Austria 2001 till 2009. Wien Klin Wochenschr. 2011 Oct;123(1920):593-8.

6. VENICE III. Vaccine European New Integrated Collaboration Effort [Internet]. [cited 2016 Sep 20]. Available from: http://venice.cineca.org.

7. Resolution WHA56.19. Prevention and control of influenza pandemics and annual epidemics. In: Fifty-sixth World Health Assembly, Geneva, 19-28 May 2003, resolutions and decisions, annexes. Geneva: WHO; 2003. p. 38-40.

8. Commission of The European Communities. Proposal for a Council Recommendation on seasonal influenza vaccination [Internet]. Brussels: Commission of The European Communities; 2009 [cited 2016 Jun 16]. Available from: http://ec.europa.eu/health/vaccination/key_documents/ index_en.htm.

9. Hoffman K, Paget J, Wojczewski S, Katic M, Maier M, Soldo D. Influenza vaccination prevalence and demographic factors of patients and GPs in primary care in Austria and Croatia: a cross-sectional comparative study in the framework of the APRES project. Eur J Public Health. 2016;26(3):395-401.
10. European Centre for Disease Prevention and Control. Seasonal influenza vaccination and antiviral use in Europe - Overview of vaccination recommendations and coverage rates in the EU Member States for the 2013-14 and 2014-15 influenza seasons. Stockholm: ECDC; 2016.

11. Palache A, Oriol-Mathieu V, Fino M, Xydia-Charmanta M; Influenza Vaccine Supply task force (IFPMA IVS). Seasonal influenza vaccine dose distribution in 195 countries (2004-2013): Little progress in estimated global vaccination coverage. Vaccine. 2015 Oct 13;33(42):5598-5605.

12. Kunze U, Groman E, Böhm G, Kunze M. Influenza vaccination in Austria, 1982-2003. Wien Med Wochenschr. 2007;157(5-6):98-101.

13. Kunze U, Böhm G, Groman E. Influenza vaccination in Austria, $1982-$ 201: a country resistant to influenza prevention and control. Vaccine. 2013 Oct 17;31(44):5099-103.

14. Austrian vaccination recommendation committee 2016. Vaccination schedule 2016 [Internet]. Vienna: Federal Ministry of Labour, Social Affairs, Health and Consumer Protection [cited 2016 Jun 9]. Available from: http://bmg.gv.at/home/Impfplan. (In German.)

15. Fedson DS, Hannoun C, Leese J, Sprenger MJ, Hampson AW, BroJørgensen $\mathrm{K}$, et al. Influenza vaccination in 18 developed countries, 1980-1992. Vaccine. 1995 May;13(7):623-7.

16. Fedson DS, Hirota Y, Shin HK, Cambillard PE, Kiely J, Ambrosch F, et al. Influenza vaccination in 22 developed countries: an update to 1995. Vaccine. 1997 Oct;15(14):1506-11.

17. Van Essen GA, Palache AM, Forleo E, Fedson DS. Influenza vaccination in 2000: recommendations and vaccine use in 50 developed and rapidly developing countries. Vaccine. 2003;21(16):1780-5.

18. Macroepidemiology of Influenza Vaccination (MIV) Study Group. The macro-epidemiology of influenza vaccination in 56 countries, 1997-2003. Vaccine. 2005 Oct 25;23(44):5133-43.

19. Palache A. Seasonal influenza vaccine provision in 157 countries (20042009) and the potential influence of national public health policies. Vaccine. 2011;29(51):9459-66.

20. The International Federation of Pharmaceutical Manufacturers and Associations Influenza Vaccine Supply (IFPMA IVS) Task Force. Influenza vaccine distribution in 141 countries, 2004-2007. ESWI Third European Influenza Conference; 2008 Sep 14-17; Vilamoura, Portugal.

21. Commission staff working document. State of play on implementation of the Council Recommendation of 22 December 2009 on seasonal influenza vaccination (2009/1019/EU) [Internet]. Brussels: European Commission; 2014 [cited 2016 Jun 15]. Available from: http://ec.europa.eu/health/ vaccination/key_documents/index_en.htm.

22. World Health Organization. Global Action Plan for Influenza Vaccines (GAP) [Internet]. Geneva: WHO [cited 2016 Jun 15]. Available from: http://www.who.int/influenza_vaccines_plan/en/.

23. Preaud E, Durand L, Macabeo B, Farkas N, Sloesen B, Palache A, et al. Annual public health and economic benefits of seasonal influenza vaccination: a European estimate. BMC Public Health. 2014;14:813. doi: 10.1186/1471-2458-14-813.

24. Hoffmann K, van Bijnen EM, George A, Kutalek R, Jirovsky E, Wojczewski $\mathrm{S}$, et al. Associations between the prevalence of influenza vaccination and patient's knowledge about antibiotics: a cross-sectional study in the framework of the APRES-project in Austria. BMC Public Health. 2015;15:981. doi: 10.1186/s12889-015-2297-x.

25. Statistics Austria. Average population in the years $1981-2018$ according to gender, wide age groups and nationality [Internet]. Vienna: Statistics Austria; 2019 [cited 2019 Mar 25]. Available from: http://www.statistik.at/web_de/statistiken/menschen_und_gesellschaft/bevoelkerung/ bevoelkerungsstand_und_veraenderung/bevoelkerung_im_jahresdurchschnitt/031331.html. 